DOI: https://doi.org/10.24867/13GI17Pavlovic

\title{
PROCES IZGRADNJE BRENDA ZASNOVAN NA KOMUNIKACIJI NA DRUŠTVENIM MREŽAMA
}

\section{THE BRAND BUILDING PROCESS BASED ON SOCIAL NETWORKS COMMUNICATION}

\author{
Nataša Pavlović, Fakultet tehničkih nauka, Novi Sad
}

\begin{abstract}
Oblast - INŽENJERSKI MENADŽMENT
Kratak sadržaj - Ekspanzija interneta je započela onog momenta kada je veći deo populacije mogao sebi da priušti kompjuter. Danas gotovo da ne postoji kuća u svetu bez kompjutera i mogućnosti pristupa internetu. Internet nije samo promenio živote ljudi, već je uticao $i$ na promene poslovanja kompanija i finansijskih institucija. Informacione tehnologije su kreirale savremeno poslovno okruženje, menjajući poslovne strategije i poslovne sisteme. Elektronsko poslovanje je doprinelo razvoju mnogih platformi za ostvarivanje konkurentske prednosti. Jedan od osnovnih argumenata za promovisanje na društvenim mrežama jeste da tradicionalni marketing gubi svoj uticaj na potrošače što je podržano od strane statističkih dokaza koji pokazuju rastući trend potrošača da donese odluke o kupovini zasnovane na internet istraživanjima i preporukama. Potrošači su skloniji da veruju povratnim informacijama od istomišljenika nego korporativnog marktinga putem televizije, radija ili novina.
\end{abstract}

Ključne reči: društvene mreže, promocija, poslovanje, brend

Abstract - The expansions of the internet began when most of the population could affored a computer. Today, there is almost no house in the world without a computer and ability to access the internet. The internet has not only changed people's lives, but has also influences changes in the business of companies and financial institutions. Information technologies have created a modern business environment, changing business strategies and business systems. E-business has contributed to the development of many platforms to gain a competitive advantage. One of the basic arguments for social media promotion is that traditional marketing is losing its impact on consumers, supported by statistical evidence showing a growing trend of consumers to make purchasing decisions based on internet research and recommendations. Consumers are more likely to trust feedback from like-minded people than corporate marketing through television, radio or newspapers.

Keywords: social networks, promotion, business, brand

\section{NAPOMENA:}

Ovaj rad proistekao je iz master rada čiji mentor je bila doc. dr Jelena Spajić.

\section{UVOD}

Masovna proizvodnja i ekspanzija uniformisanih proizvoda omogućila je potrošačima da mogu da biraju šta će da kupe, ali je naterala poslovne subjekte da nešto urade po tom pitanju kako bi svoj proizvod izdvojili iz mora proizvoda koji se nude na tržištu. Kao rezultat takvih pojava i potreba javilo se brendiranje, kao način na koji kompanija teži da izgradi imidž kvalitetom svojih proizvoda ili usluga, pri čemu se teži zadovoljenju potreba korisnika. Konkurencija na globalnom tržištu podstakla je poslovne subjekte da pronađu inovativne pristupe svom poslu, ukoliko žele da opstanu na tržištu.

Čak i one kompanije sa snažnim brendom su morale svoje poslovanje da orijentišu na Internet. Brzo se shvatilo da nije dovoljno da poslovni subjekti imaju samo veb-stranicu, već je neophodno imati kreirane profile na najpopularnijim društvenim mrežama. Cilj rada jeste sagledavanje značaja brenda i čitavog procesa izgradnje brenda, uz preporuke različitih načina promocije na društvenim mrežama na primeru jednog domaćeg preduzetničkog biznisa.

\section{ZNAČAJ BRENDIRANJA U MARKETINGU}

Brend predstavlja kombinaciju imena, znaka, dizajna, simbola koji su ujedinjeni u svakom proizvodu i usluzi kompanije [1]. Brend na kompaniju ima važan i kritičan uticaj, koji oblikuje način doživljavanja kompanije i njenih proizvoda od strane potrošača, pa samim tim značajno utiče na povećanje obima poslovanja i svesti kupaca o proizvodima ili uslugama kompanije.

\subsection{Pojmovno određenje i značaj brenda}

Opšteprihvaćena definicija je data od strane američkog udruženja za marketing, koja brend definiše kao: ,ime, pojam, znak, simbol ili dizajn ili pak kombinaciju navedenog, čime se identifikuje roba ili usluga jednog prodavca ili grupe prodavaca i diferenciraju u odnosu na konkurenciju“ [2]. Brend je nematerijalno sredstvo jednog proizvoda ili usluga sa dodatnim dimenzijama koje ga/ih izdvajaju u odnosu na proizvod/usluge konkurenata. Karakteristično je da brend čine njegovi vidljivi i nevidljivi elementi. Nevidljivi elementi brenda obuhvataju sve ono što brend predstavlja, a što nije u domenu čula percepcije.

Za razliku od vidljivih elemenata koji su na površini i čine spoljašnost brenda, nevidljivi elementi predstavljaju unutrašnju energiju brenda. Nevidljive elemente brenda čine tradicija, etika, društvena odgovornost, vizija, strategija, korporativna kultura, odnosno bazične vrednosti koje preduzeće nastoji da afirmiše, interni odnosi i odnosi 
koje kompanija uspostavlja i razvija sa okruženjem, emocije koje brend emituje [3]. Pojedini autori shvataju odnos vidljivih i nevidljivih elemenata brenda kao odnos između forme i suštine (tabela 1).

Tabela 1. Elementi brenda (1)

\begin{tabular}{ll}
\hline Vidljivi elementi & Nevidljivi elementi \\
\hline Forma & Suština \\
Reči i slike & Dela/ponašanja \\
Očekivanja & Iskustvo \\
Dato obećanje & Ispunjeno obećanje \\
\hline
\end{tabular}

\subsection{Brendiranje na Internetu}

Internet brendiranje se može definisati kao tehnika upravljanja brendom koja koristi internet (veb stranice i društvene medije) kao medij za pozicioniranje svog brenda na tržištu [4]. Kao cilj brendiranja na internetu može se na prvom mestu izdvojiti prepoznatljivost brenda. Brendiranje putem interneta omogućava kompanijama da utvrde svoju poziciju na tržištu. Čak i dobro pozicionirane kompanije, koje su već izgradile brend, da bi tu svoju poziciju očuvale ili se čak i proširile, potrebno je da u svoju strategiju implementiraju i strategiju internet brendiranja.

Navedeno proizilazi iz činjenice da je internet preuzeo značajnu ulogu u svakodnevnom životu potrošača. Ključna komponenta brendiranja na mreži jeste izrada veb stranice, koja se koristi za predstavljanje proizvoda i usluga, ali i same kompanije. Poenta je da veb stranica pruži pozitivnu sliku o kompaniji, pa se stoga treba fokusirati na izgled.

Brendiranje na mreži obuhvata i korišćenje blogova za generisanje sadržaja za čitaoce koji se zanimaju za teme vezane za brend. Pored veb stranice i blogova, dobra je praksa prisutnosti kompanije i na drugim veb lokacijama. Današnji uslovi su nametnuli da je za kompaniju posebno važno da bude i na društvenim mrežama. To omogućuje deljenje znanja o brenda i neprestanu komunikaciju sa potrošačima, ali i prikupljanja značajnih informacija o potrošačima, na osnovu se stiče saznanje o njihovim potrebama, kojima se prilagođavaju proizvodi i usluge kompanije. Izazovi internet brendiranja, kojih kompanija mora biti svesna [5]:

- Internet sadrži mnoštvo veb lokacija, koje su prepune brojnih informacija, stoga je prisutna informaciona preopterećenost, pa kompanije moraju da pronađu način da izrone iz mora informacija i time privuku pažnju potencijalnim i trenutnim korisnicima svojih proizvoda ili usluga.

- Upravljanje različitim kanalima komunikacije zahteva i njihovo poznavanje. Kompanije se moraju uveriti u konzistentnost sadržaja robnog brenda na određenom kanalu društvenih medija. Pored toga, izazov je i naći rešenje za rešavanje negativnih komentara i žalbi koji mogu imati negativan efekat na imidž.

- Prisutni su i etički problemi, koji podrazumevaju ostavljanje lažnih pozitivnih ili negativnih kritika na račun kompanije koja je prisutna na mreži.

Brendiranje na Internetu ne treba olako shvatiti. Naprotiv za takav oblik javnog nastupa potrebna je strategija. Ključne stvari za onlajn brendiranje su [5]:

- „Brend ,priče““

- „Portret“" brenda za svet

- Doslednost na blogu
- Brendiranje na društvenim mrežama i unakrsna promocija.“

Brend priče proističu iz iskustva potrošača sa proizvodima ili uslugama. Brend na Internetu se stvara kroz poverenje korisnika, čineći sebe autentičnijim i pristupačnijim. Brend priču na Internetu treba postaviti tako da „publika“ bude glavni junak i da se stvori utisak da kompanija služi njoj.

Kada se kreira „priča o brendu“, potrebno je da se ispriča svetu, što je najbolje uraditi putem Internata. Veb dizajn igra važnu ulogu u stvaranju suštine brenda korišćenjem logotipa, tekstova, boja, slika, zvukova i video zapisa.

Redovno ažuriranje na Internetu (veb, blog, društveni mediji), najmanje tri dana nedeljno je neophodno za izgradnju autentičnog identiteta brenda

Redovno ažurirani blogovi koji se bave pitanjima „publike“ i rešavanjima njihovim problema, može ih učiniti korisnicima usluga kompanije i uspostaviti da brend postane vidljiv $\mathrm{i}$ autoritativan $\mathrm{u}$ njihovim očima. Komentari na blogu predstavljaju inovativan način za interakciju sa kupcima i čitaocima, omogućavajući podršku korisniku, dok je prisutno efektivno prisustvo brenda.

Društvene mreže, kao što su: Twitter, Facebook, LinedIn, Instagram, Pinterest i mnoge druge, postale su moćne platforme za promociju i za brendiranje. Ključno prilikom brendiranja na društvenim mrežama jeste redovno objavljivanje.Unapređenje promocije na društvenim mrežama omogućava pratiocima da se povežu na više platformi i izaberu onu na kojoj je najugodnije pratiti kompaniju.

Pre nego što se fokus stavi na društvene mreže i promociju na tim internet platformama, treba se upoznati sa marketinškim trendovima koji će omogućiti izgradnju, proširenje i održavanje i brendova (slika 1).

\subsection{Korišćenje društvenih mreža u promociji}

Društvene mreže su postale jedna od ključnih stavki direktnog marketinga za izgradnju uspešnog odnosa sa potrošačima.

Ovaj oblik interaktivnog komuniciranja dovodi do brzog i efikasnog transfera informacija.

Ono što društvene mreže izdvaja u odnosu na druge oblike promocije jeste širok auditorijum, dvosmerna komunikacija, mogućnost plasiranja individualizovanog sadržaja i niski troškovi.

Kada je kompanija prisutna na društvenim mrežama, ona tako potrošačima da je do znanja da joj je stalo do njih, odnosno do njihovog mišljenja i satisfakcije. Blogovi korisnika i njihovi komentari na profilima kompanije predstavljaju korisne povratne informacije.

Tu treba uzeti u obzir i negativne komentare, na koje kompanija mora blagovremeno odgovoriti ili primenjivati neke od alata koji blokiraju takve komentare. Na osnovu izloženog, evidentno je da društvene mreže omogućuju kompanijama da sa potrošačima izgrade čvršće i trajnije veze, što rezultira povećanjem prodaje i ponovnim kupovinama. 


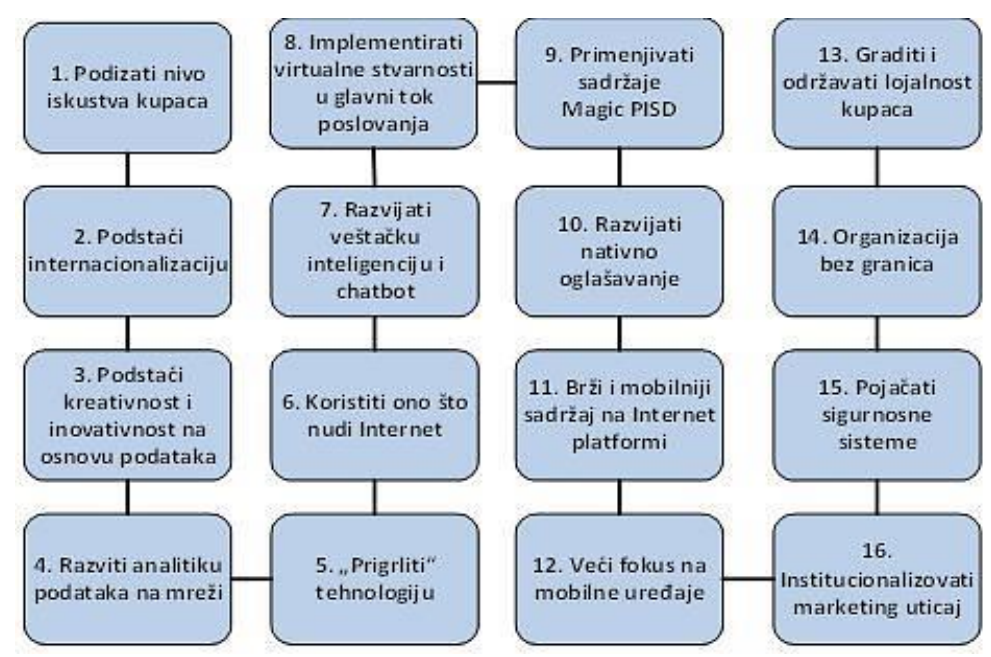

Slika 1. Marketinški trendovi koji će omogućiti izgradnju, proširenje i održavanje i brendova [6]

Prostorno i vremenski neograničena komunikacija izdvaja društvene mreže kao potencijalno efikasan promotivni kanal [7].

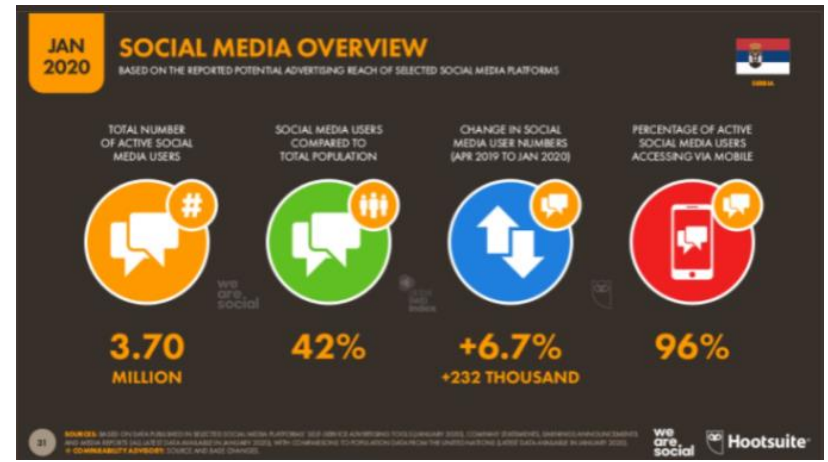

Slika 2. Korisnici društvenih mreža u Srbiji [8]

Kada je reč o Srbiji, korisnika interneta u januaru 2020. godine bilo je 6,57 miliona. Na slici 2. je prikazano da kada je reč o društvenim mrežama došlo je do povećanja korisnika za 232000 između aprila 2019.godine i januara 2020.godine, a to je za $6,7 \%$ više korisnika društvenih mreža. U januaru 2020. Srbija ima 3,70 miliona korisnika društvenih mreža, od kojih su $96 \%$ aktivni korisnici na svojim mobilnim telefonima.

Marketing na društvenim mrežama podrazumeva upotrebu platforme kako bi se kompanije povezale sa svojom publikom, izgradile svoj brend, povećale promet i pokrenule prodaju na veb-lokaciji. To podrazumeva redovno objavljivanje sadržaja na profilima, slušanje i angažovanje pratilaca, analizu rezultata i pokretanje promotivnih poruka na društvenim medijima. Treba naglasiti da kompanije ne treba da zanemare postojanje alata za upravljanje društvenim mrežama, koji će pomoći da se postigne uspeh u marketingu na društvenim mrežama.

Prilikom kreiranja strategije za promociju na društvenim mrežama, poslovni subjekti moraju da poštuju određena pravila [9]:

\section{Sadržaj: Blagovremeno i redovno angažovanje u sadržaju koji odgovara kupcu}

Navedeno podrazumeva da postavljane informacija na društvenim mrežama treba da bude rutina, što znači da banke moraju da održavaju aktivno prisustvo i redovnu komunikaciju na društvenim mrežama.

\section{Jasnoća: Jasna poruka o poslovnom subjektu i proizvodima/uslugama}

Kako bi rezultati promocije na društvenoj mreži bili pozitivni, potrebno je da komunikacija bude jasna i da omogući stvaranje, održavanje ili proširenje brenda.

\section{Doslednost: Promovisati doslednu poruku}

Potrebno je uskladiti angažovanje na svim platformama društvnih mreža na kojima se sprovodi promocija. To podrazumeva konzistentnost u porukama koje se plasiraju na društvenim mrežama.

\section{Usklađenost: Uskladiti mehanizme sa regulatornim telima}

Priroda društvenih mreža je dinamična i otvorena, stoga je potrebno da kompanija uskladi sadržaj sa propisima i kulturom zemlje u kojoj posluje.

\section{PROCES IZGRADNJE BRENDA NA DRUŠTVENIM MREŽAMA NA PRIMERU PREDUZETNIČKOG BIZNISA}

Kako bi se videlo na koji način se može uticati na izgradnju brenda na društvenim mrežama, u radu je izvršena analiza izgradnje brenda kozmetičkog salona Coco Nalis Studio (CNS). Svoj prepoznatljivi brend salon je izgradio upravo efektivnom komunikacijom na društvenim mrežama.

S obzirom da je kompanija na društvenoj mreži Instagram registrovana kao biznis stranica dostupni su i određeni statistički podaci i metrike o samim posetama datoj stranici kao i pregledima, koje pružaju dragoceni uvid u onlajn ponašanje pratilaca i pomažu u unapređenju sadržaja koji se plasira ovoj društvenoj mreži.

Impressions ili utisci na društvenoj mreži Instagram pokazuje broj prikazivanja instagram posta, storija ili IGTV videa na ekranima korisnika instagram mreže $\mathrm{u}$ određenom vremenskom periodu. Termini Impressions (utisci) i Reach (dostizanje) nemaju isto značenje i podjednako su bitni. Dostizanje predstavlja ukupan broj profila koji su videli objavu, dok utisci prikazuju koliko se puta objava prikazala na ekranu korisnika društvene mreže Instagram. Instragram statistika za period od 27.oktobra do 2. novembra prikazuje da je Impressions za CNS bio $+4,1 \%$ u odnosu na prethodnu nedelju, odnosno da se objava@coconails_ns profila pojavila 44.160 puta na ekranima korisnika (slika 3). 
Impressions

$+4.1 \%$ vs Oct 20 - Oct 26

44,160

\section{Slika 3. Broj prikazivanja instragram objava na ekranima korisnika}

Posmatrano preduzeće Coco Nails Studio, u nastavku CNS plaća promocije na društvenim mrežama kako bi što više klijenata čuli za studio. Zahvaljujući tome jedan video klip koji je pokazivao baznu obuku za tehniku gel lak je pregledan više od 39.000 puta, što je jako značajno za profil brenda koji na Instagramu ima oko 4000 pratilaca, te stoga broj pregleda koji je skoro 10 puta veći od broja pratilaca predstavlja izuzetan uspeh. U danima kada je promocija aktivna povećava se Impressions Reach Instagram stranice. Za vreme promocije video klipa koji je pokazivao baznu obuku, broj profila koji su pregledali sponzorisanu objavu bio je 50.811, od čega $96 \%$ profila nije pratilo profil $C N S$, a $86 \%$ su došli do objave preko promocije. Broj prikazivanja objava je takodje porastao sa promocijom i iznosio je čak 123.320 (što označava koliko puta se objava pojavila na ekranima korisnika Instagram mreže).

\section{ZAKLJUČAK}

U današnjem konkurentnom svetu brendiranje i brend je glavna tema. Kada potrošači čuju ili vide naziv poslovnog subjekta javljaju se sećanja vezana za taj naziv što $u$ značajnoj meri utiče na njihovu kupovinu. Ta sećanja su osnov brenda. Brendiranje je danas prioritet marketinga. Brend predstavlja veoma značajno sredstvo nematerijalnih ulaganja, jer pojam koji brend predstavlja potrošačima određuje da li kompanija pruža potrošačima ono što oni žele u pogledu kvaliteta, poverenja, asortimana, imidža, osećaja pripadnosti. Razvoj Interneta i njegova masovna popularizacija omogućila ja poslovnim subjektima novi način za globalnu tržišnu komunikaciju i promociju. Prednost Interneta prilikom brendiranja proizvoda ogleda se u činjenici što omogućava prikupljanje informacija o potrebama i željama potrošača.

Da bi se brend pozicionirao na internetu, potrebno je da bude plasiran i promovisan preko veb-sajta ili nekih od kanala društvenih mreža. Nastup poslovnih subjekata na društvenim mrežama je potrebno ozbiljno shvatiti i taj deo poslovanja obavezno ugraditi u strategiju poslovanja.

Istraživanje i analiza u praktičnom delu ovog rada, pokazali su da je preduzeće $C N S$ uspelo da izgradi prepoznatljiv brend na teritoriji grada Novog Sada i to na osnovu efektivne komunikacije na društvenim mrežama. Stoga se može reći da je u današnje vreme izgradnja brenda putem društvenih mreža moguća uz pažljivo planiranje sadržaja stranice, targetiranje ciljne grupe, efektivnog komuniciranja i naravno dobro podešenih parametra za promociju objava potencijalnim i stalnim klijentima.

\section{LITERATURA}

[1] 1. Nikolić, Stanković, Dejanović. Brend menadžment. Novi Sad: Fakultet tehničkih nauka Univerziteta u Novom Sadu, 2015.

[2] 2. P., Kotler. "Marketing menadžment. Evanston : Univerzitet Northwestern, 2006.

[3] 3. Z., Gavrilović. Internet brendiranje. Bijeljina : Univerzitet u Istočnom Sarajevu, Fakultet poslovne ekonomije, 2015.

[4] 4. S., Brogi. Online brend communities: a literature review. Roma: Univerzitet of Roma Tor Vergata, 2014.

[5] 5. Element 7 Digital. [Online] [Cited: 1010 2020.] https://element7digital.com.au/blog/4-killer-ideas-tobe-an-online-brand-maniac.

[6] 6. Kirtus K., Karahan F. To Be or Not to Be in Social Media Arena as the Most Cost- Efficient Marketing Strategy after the Global Recession. s.l.: Procedia Social and Behavioral Sciences, 2011.

[7] 7. Data Reportal. [Online] [Cited: 2012 2020.] https://datareportal.com/reports/digital-2020-serbia.

[8] 8. Capgemini. [Online] [Cited: 1310 2020.] http://www.capgemini.com/resource-fileaccess/resource/pdf/social_banking_leveraging_social media_to_enhance_customer_engagement.pdf.

[9] 9. Vasiljev S, Sudarević T. Marketing principi. s.1. : Prometej Novi Sad, 2014.

\section{Kratka biografija:}

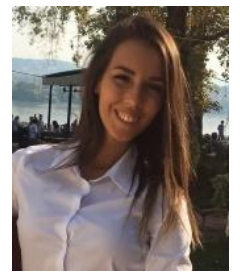

Nataša Pavlović rođena je u Novom Sadu 1994. god. Master rad na Fakultetu tehničkih nauka iz oblasti Inženjerski menadžment odbranila je 2020.god. kontakt: pavlovicnatasa021@gmail.com 